\title{
ULTRANEOLIBERALISMO E BOLSONARISMO: IMPACTOS SOBRE O ORÇAMENTO PÚBLICO E A POLÍTICA SOCIAL*
}

Elaine Rossetti Behring

Juliana Fiúra Cislaghi

Giselle Soura

\section{Introdução}

O presente capítulo caracteriza o novo regime fiscal, a partir de 2016, como um desdobramento do ambiente de ajuste fiscal permanente no Brasil da redemocratização. Aborda a particularidade do ultraneoliberalismo, em especial no governo Bolsonaro, com destaque aos impactos da EC 95. Analisa as peças orçamentárias (PPA, LDO 2020 e LOA 2020) do governo federal e as tendências e condições de financiamento das políticas sociais sob o governo Bolsonaro. E aborda os significados da mais recente contrarreforma da Previdência, na sua relação com o novo regime fiscal e a condição geral da classe trabalhadora. Finalizamos apontando traços e tensões do ambiente explosivo de encontro entre ultraneoliberalismo e neofascismo no país, no ambiente de crise do capitalismo, acirrado pela pandemia mundial da COVID-19. O artigo é produto parcial dos debates e investigações que vem se desenvolvendo no âmbito do Grupo de Estudos e Pesquisas do Orçamento Público e da Seguridade Social (GOPSS/ CNPq), que completa em 2020 seus 17 anos de existência, e faz parte do Centro de Estudos Octávio Ianni (CEOI/CNPq). Ambos os espaços vêm reunindo docentes e estudantes de pós-graduação e graduação, sendo importantes lugares de sustentação da produção científica crítica no âmbito do PPGSS/UERJ.

\section{Ajuste fiscal permanente e ultraneoliberalismo}

Desde os primeiros dias de 2019, a partir da posse do governo Bolsonaro, seu superministro da Economia, Paulo Guedes, apresentou medidas que, no conjunto, pretendiam atacar o "déficit das contas públicas" e criar gatilhos para situações que qualificavam como "emergência fiscal". Sustentamos aqui

*DOI - 10.29388/978-65-86678-20-8-0-f.103-122 
que estamos diante do capítulo mais recente do ambiente de ajuste fiscal permanente com o qual o Brasil vem convivendo ao longo da redemocratização com nuances diferentes entre os governos, mas que não alteraram significativamente a ideia de "estabilidade econômica a qualquer custo". Tal orientação geral se manteve nos anos lulopetistas, quando houve alguns leves e insuficientes deslocamentos, mas que causaram impactos reais na vida de milhões de trabalhadores e trabalhadoras, que incomodaram sobremaneira as classes dominantes brasileiras. Porém, mesmo naqueles treze anos (2003 - 2015), diferente dos laudatórios discursos sobre um suposto neodesenvolvimentismo e uma mítica "nova classe média", não ultrapassamos uma espécie de neoliberalismo de cooptação (Cislaghi, 2020).

Essa faceta do neoliberalismo emerge como resposta às lutas de movimentos sociais em todo mundo no início dos anos 2000 contra os efeitos perversos desse modelo econômico. Essas lutas impulsionaram a chegada ao poder de antigos representantes de partidos da classe trabalhadora, como Lula no Brasil e Tony Blair na Inglaterra. Esse ascenso de governos chamados progressistas, principalmente na América Latina, no entanto, não reverteu e sequer interrompeu a aplicação do receituário neoliberal em sua essência. Esses governos, entretanto, apropriaram-se das pautas de reconhecimento que, associadas a políticas sociais focalizadas, cooptaram lideranças sindicais, feministas, de movimentos antirracistas e LGBTQs para formação de um novo consenso, o que Fraser (2016) chama de neoliberalismo progressista. No Brasil, o neoliberalismo progressista adquire fortes características de cooptação de lideranças sindicais, que passam a ocupar cargos no governo e administrar fundos de pensão, favorecendo dessa forma seus interesses materiais em associação com os interesses do capital financeiro por meio de seu acesso privilegiado ao fundo público (Oliveira, 2003 e Braga, 2012).

A economia política brasileira navegou, entre 1994 e 2016, sob o tacão: do superávit primário, a partir de 1999 quando houve nosso último acordo com o FMI; da Lei de Responsabilidade Fiscal (2000); da desvinculação (desde 1994, com o Fundo Social de Emergência - FSE e que veio a se transformar na Desvinculação de Receitas da União - DRU) e contingenciamento anuais de recursos das políticas públicas e sociais; da lógica das parcerias público-privadas e organizações sociais do setor público não-estatal contidos no Plano Diretor da Reforma do Estado (1995), um documento orientador de todo o período, e que continha ataques virulentos às conquistas sociais e ao regime jurídico único dos servidores públicos (Behring, 2003 e 2019 e Oliveira, 2019). Ali estava enunciado o mote de que a crise seria do Estado, e de que o controle das contas públicas se- 
ria a única alavanca para um ambiente "saudável" de negócios e criação de infraestruturas. É interessante observar que as medidas enunciadas em 1995 foram largamente implementadas desde então, destacadamente as seguidas contrarreformas da previdência (1998, 2003, 2015 e 2019), e a cada investida, a crise se manteve na sequência como uma espécie de "espada de Dâmocles" a nos ameaçar a todas e todos.

No entanto, é preciso enfatizar, o que estamos vivendo hoje não é apenas mais uma mudança de pele, não é "mais do mesmo". E por algumas razões. Desde 2016, estamos sob um golpe de Estado de novo tipo (Demier, 2017), que tem em seu cerne o aprofundamento do ajuste fiscal, chamado de Novo Regime Fiscal, tendo em vista sinalizar ao mercado um ambiente de negócios que assegura "trabalhadores livres como os pássaros" para aceitarem qualquer trabalho precarizado; e, de outro lado, assegurar o saque ao fundo público, como um suporte imprescindível para o grande capital em tempos de crise destacadamente os detentores de títulos da dívida pública. Este processo se combina ao saque do patrimônio público, com a retomada das privatizações, com destaque aos interesses imperialistas sobre as riquezas do país, destacadamente a água, o petróleo e a Amazônia. As medidas do governo golpista de Temer, algumas delas decididas sob bombas na Esplanada dos Ministérios, não deixam qualquer sombra de dúvida. Dentre outras, tivemos: a contrarreforma trabalhista que estimula a terceirização e precarização generalizadas do trabalho no país; a aprovação da Emenda Constitucional 95, que praticamente congela os gastos primários do governo federal fazendo com que sejam corrigidos apenas pela variação da inflação do ano anterior (em tempos de deflação e paralisação da atividade econômica) e preserva a dívida pública, a grande gambiarra de recursos públicos; e a Emenda Constitucional 93, que estendeu a desvinculação de recursos pela DRU até 2023 e a ampliou para 30\%, também para estados e municípios. Temer propunha ainda uma contrarreforma da previdência, mas não teve correlação de forças para avançar, sob uma saraivada de denúncias de corrupção. Essa possibilidade só foi configurada com a legitimidade das urnas com as eleições gerais de 2018, ainda que fundada num ambiente antidemocrático, com a prisão de Lula e as fakenewss, hoje sob investigação pelo STF. Ou seja, é preciso ficar claro que o ambiente político e ideológico para que medidas tão agressivas aos direitos e condições de vida e trabalho das maiorias sejam tomadas, é de profundo ataque às liberdades democráticas, de uma ainda mais feroz blindagem da democracia (Demier, 2017). E é evidente, sob o governo Bolsonaro, que o apreço de Guedes pelas prerrogativas que a democracia burguesa assegurou historicamente, a partir da presença dos trabalhadores(as) na cena 
pública, está na proporção de sua participação na ditadura sanguinária de Augusto Pinochet, no Chile, que ele caracterizou em recente e bombástica reunião ministerial $1^{1}$ como "reconstrução" daquele país.

Portanto, estamos diante do momento mais dramático para os trabalhadores(as) desta saga ortodoxa e destrutiva: o ultraneoliberalismo. O discurso é muito semelhante ao dos anos 90: a crise é do Estado e é necessário que "cada um faça a sua parte" no processo de socialização dos seus custos. Mas no mundo real, ontem e hoje ainda mais, quem paga a conta são os(as) trabalhadores(as), o que se evidencia no recrudescimento dos indicadores sociais brasileiros, destacadamente nos últimos quatro anos. Vejamos, para além da contrarreforma da previdência que trataremos em item específico adiante, mas em conexão com ela, alguns elementos do pacote draconiano de medidas de Guedes e Bolsonaro. Cabe notar que, mesmo com a inflexão da pandemia da COVID-19 desde março de 2020, não houve recuo na agenda ultraneoliberal, que combinada à crise sanitária, vem tendo resultados catastróficos ${ }^{2}$, assumindo um perfil de genocídio em massa e que atinge, sobretudo, a classe trabalhadora em seus setores mais empobrecidos, a partir de um discurso que submete a defesa da vida à economia. Na verdade, a pandemia desnudou a agressividade do ultraneoliberalismo.

Entendemos por ultraneoliberalismo essa mais recente forma do neoliberalismo, que não se resume ao Brasil, pois pode ser observada em vários países no mundo. A maioria dos autores do campo crítico, adotando ou não esse termo, concordam que o neoliberalismo sofre uma inflexão que aprofunda seus pressupostos, como consequência da crise financeira de 2008. Apesar de a crise ser centralmente das atividades do setor privado financeiro, e fazer parte de um momento estrutural de crise do capital que se arrasta por décadas, ela foi apresentada, mais uma vez, como uma crise do Estado, que de fato, absorveu os prejuízos do capital por meio de fundo público, com a justificativa de que bancos e instituições financeiras eram "grandes demais para quebrar" o que afetaria o conjunto da sociedade. Dardot e Laval (2019) que utilizam para caracterizar esse momento a expressão "novo neoliberalismo", afirmam que, apesar dos movimentos de resistência como o Occupy Wall Streetnos EUA ou a vitória elei-

\footnotetext{
${ }^{1}$ Trata-se da filmagem da Reunião Ministerial de 22 de maio de 2020, no Palácio do Planalto, cujo conteúdo estarrecedor veio a público, por decisão do STF, no contexto da crise institucional gerada pelo embate entre Bolsonaro e seu ex-ministro da Justiça, Sérgio Moro.

${ }^{2}$ No momento em que escrevemos essas linhas, o Brasil é o epicentro da pandemia e já contabiliza mais de 37 mil mortos.
} 
toral da esquerda na Grécia, o neoliberalismo não só sobreviveu como se radicalizou, porque o neoliberalismo se utiliza das crises econômicas que ele gera para reforçar sua própria lógica, bloqueando os caminhos alternativos. Vejamos sua expressão brasileira.

Guedes foi à grande mídia no dia 5 de novembro de 2019 para falar de um "novo pacto federativo" e da necessidade de uma "nova cultura de responsabilidade fiscal", como se a Lei de Responsabilidade Fiscal e a EC 95 não fossem suficientemente duras, apresentando ao Congresso três propostas de Emenda Constitucional, complexas e cheias de armadilhas. A proposta de EC do Pacto Federativo (Mais Brasil) acena a inversão do percentual de alocação dos royalties do petróleo que cabem ao governo federal, que passaria para $70 \%$ para estados e municípios e 30\% para a União, gerando uma distribuição de 400 bilhões ao longo de 15 anos, diretamente aos demais entes federativos. A arrecadação federal do salário-educação - 9,8 bilhões - também iria para os entes federativos subnacionais. As contrapartidas dos estados envolveriam renunciar os contenciosos com o governo federal em torno de questões tributárias (Lei Kandir sobre isenções tributárias de ICMS sobre exportações, por exemplo). E, também, o apoio à inclusão de estados e municípios na contrarreforma da previdência, num contraponto à desidratação que esta teria sofrido no Congresso, segundo a equipe econômica. Já os municípios que têm menos de 5 mil habitantes teriam que provar que arrecadam $10 \%$ de sua receita para continuar existindo, o que colocou em questão cerca de 1.254 cidades brasileiras. Se houve muita irracionalidade, oportunismo e clientelismo político na criação de municípios, esse é um tema delicado que envolve a heterogeneidade estrutural brasileira e processos locais, e ainda mais espinhoso quando vem de cima para baixo, sem qualquer diálogo.

Havia na proposta a criação de um limite para benefícios tributários, os quais têm de fato causado perdas de mais de 4\% do PIB na arrecadação, o que vimos criticando e sinalizando (Cf. Salvador, 2017 e 2019), e que não poderiam ultrapassar 2\% do PIB até 2026. Aqui caberia discutir sobre quais tributos e setores recaem as isenções fiscais ou gastos tributários, já que nossa crítica se dirige ao impacto das mesmas sobre os recursos das políticas sociais, bem como ao interesse público dessas medidas de uma forma geral. No caso do Rio de Janeiro, por exemplo, um dos elementos criminosos revelados sobre governadores presos dizia respeito aos gastos tributários que não respondiam a qualquer interesse público e mais se pareciam com agrados aos parceiros privados em detrimento do interesse público e da área social. Sabe-se que está em curso a proposição de uma "reforma" tributária que poderá descaracterizar profundamente o 
financiamento, por exemplo, da seguridade social. Assim, tudo indica que a diminuição das isenções provavelmente não vai impactar o aumento de recursos para a área social. Ao lado disso, quebra-se a lógica orçamentária constitucional que articulava planejamento e orçamento, com a extinção do Plano Plurianual (PPA) - que vem sendo esvaziado progressivamente desde o governo Dilma -, o que traria maior flexibilidade ao orçamento público, do ponto de vista da proposta. A nosso ver, o que temos é o presenteísmo absoluto na formulação de políticas públicas, a inexistência de planejamento de médio prazo (ver abaixo a análise das peças orçamentárias do governo atual). Outro aspecto é que a União passaria a não dar suporte a entes federativos endividados a partir de 2026, exceto em operações internacionais, o que significa um "cada um por si" federativo, nos termos da ótima crítica de Guilherme Santos Melo, que caracterizou o pacote no seu conjunto como uma espécie de "AI-5 econômico", num breve comentário nas redes sociais. Com a implementação da calamidade pública a partir de março de 2020, esta proposta ficou em stand by quanto a alguns destes aspectos. No entanto, o suporte aos demais entes federativos para fazer frente aos impactos da pandemia foi condicionado ao congelamento dos salários e progressões no serviço público, como segue, medida que já era enunciada antes da pandemia.

$\mathrm{O}$ ataque mais duro se dá, portanto, sobre trabalhadores(as) do serviço público, mais uma vez transformados na Geni, personagem da genial Ópera do Malandro de Chico Buarque de Holanda (1977/1978), atacada sob pedras e dejetos. Desde a inauguração do neoliberalismo entre nós com Collor - quem não se lembra dos discursos sobre os marajás? -, e passando pelo Plano Diretor da Reforma do Estado (1995), de Fernando Henrique Cardoso e Bresser Pereira, com seus ataques ao Regime Jurídico Único e à Constituição "perdulária" de 1988, a sanha do mainstream econômico sobre o serviço público encontrou poucos freios (Oliveira, 2019). Os governos do PT recompuseram o quadro de pessoal com concursos públicos em várias áreas (o quadro de assistentes sociais do INSS, é um exemplo, dentre outros), mas também aprovaram contrarreformas como a da previdência em 2003, o FUNPRESP de 2012 e o incentivo às organizações sociais e similares (EBSERH e outros) que fragilizam o serviço público na ponta da implementação de políticas centrais, pois têm a função precípua de contratar trabalhadores(as) com vínculos não estáveis.

Mas agora o cenário é bem pior: fala-se da possibilidade de cortar até $25 \%$ dos salários dos trabalhadores em caso de "emergência fiscal" 3 com redu-

\footnotetext{
${ }^{3} \mathrm{O}$ que foi lembrado pelo governo no contexto da pandemia, quando mais uma vez os servidores públicos foram convocados a "fazer sua parte", ainda que em sua
} 
ção proporcional da carga horária por até dois anos, com a justificativa de reduzir as despesas obrigatórias em período de crise. Como estamos em plena crise no momento ainda mais agravada pela pandemia - e o governo federal e vários estados vêm descumprindo a regra de ouro, segundo a qual não podem contrair dívidas para fazer frente as despesas correntes, tal medida seria de aplicação imediata e ao mesmo tempo vigoraria como gatilho em crises futuras. Guedes queria economizar 28 bilhões de reais em dois anos, sobre as costas dos trabalhadores do serviço público, o que vem acompanhado da suspensão de progressão funcional (exceto de juízes, ministério público, militares e diplomatas, digase dos mais altos salários do país), suspensão de concursos, suspensão de licenças de capacitação, congelamento dos salários, reestruturação de carreiras, e perseguição de funcionários que tenham filiação partidária, que perderiam a estabilidade. Sobre essa condição dos(as) trabalhadores(as) do setor público no contexto de um ajuste fiscal permanente, Gênesis Oliveira (2019) mostra o aumento das atividades terceirizáveis de 13, em 1997, para 31, em 2018, a implementação de regras que dificultam o concurso público (Decreto 9739/2019), o aumento do gasto público com terceirizações e a queda percentual progressiva do gasto público com pessoal, de 10\% do OGU, em 2019, para 9,4\% em 2020. São dados inequívocos da socialização dos custos da crise com base na apropriação da renda dos trabalhadores do serviço público, vilipendiando suas condições de trabalho para a apropriação de fundo público para outras finalidades, o que evidentemente compromete a oferta de serviços.

Outro aspecto é a proposta de unificar os pisos da educação e saúde, deixando aos estados e municípios a tarefa de alocar $37 \%$ de seus recursos nas duas políticas. A proposta inicial previa uma redução de gastos nessas políticas centrais e a inclusão dos inativos no percentual, o que na prática reduziria o orçamento, mas houve recuo diante da saraivada de críticas até nas hostes governistas. Há, ainda, a criação do Conselho Fiscal da República, com participação de representações dos entes federativos, que teria a tarefa de monitorar ações e gerar a tal cultura de responsabilidade fiscal. Evidentemente, é um conselho tecnocrático e judicial (o que vem sendo questionado, considerando a autonomia dos poderes) e sem qualquer participação de trabalhadores(as). Por fim, temos a Emenda Constitucional dos Fundos, que recolhe 220 bilhões de fundos setoriais que estão "parados" (ou foram parados?), afetando 248 fundos (dentre eles fundos de políticas sociais ou de interesse público), e cujo objetivo é centralmente pagar a dívida pública - em 2019, em torno de 5,5 trilhões, equivalente a

esmagadora maioria não obtenham supersalários. O corte de salários não foi aprovado na calamidade pública de 2020 , mas o congelamento sim. 
79\% do PIB brasileiro, o que mostra que o sacrifício sugerido penaliza o país, mas afeta muito pouco a dinâmica da dívida, colada à taxa Selic. Com os custos da pandemia sobre o crescimento econômico, há previsões de que a relação dívida/PIB chegue a mais de $95 \%$ nos próximos anos. Existia alguma previsão de alocação desses recursos dos fundos para políticas de combate à pobreza e investimentos de infraestrutura, mas o acompanhamento que vimos fazendo do orçamento nos diz que tal menção são lantejoulas para tornar a proposta mais atraente. Há uma desindexação das despesas obrigatórias que passam a não ser corrigidas pela inflação abrindo o flanco para sua redução, exceto a previdência e o BPC. Esse pacote se combina a uma ofensiva quanto às privatizações, com destaque para a Eletrobrás, mas que inclui até a Casa da Moeda, e como viemos, a saber, mais recentemente com a divulgação da sinistra Reunião Ministerial de 22 de maio de 2020, o Banco do Brasil.

\section{O orçamento de Bolsonaro: institucionalização das de- sigualdades sociais}

Nas linhas que seguem, realizamos a análise das peças orçamentárias do governo Bolsonaro, que corroboram a perspectiva do ultraneoliberalismo, conforme se verá. A análise do orçamento do governo Bolsonaro deve abordar a metodologia adotada pelo governo, o que transparece na apresentação das metas no Plano Plurianual 2020 a 2023. O PPA representa (ou deveria representar) um planejamento estratégico dos governos para 4 anos. Tal instrumento orçamentário é fundamental por apresentar as prioridades, metas e objetivos a serem cumpridos. A descontinuidade metodológica e a falta de compromisso com as diretrizes nele propostas, vêm esvaziando seu conteúdo político e técnico desde 2012, e o torna uma peça orçamentária frágil diante das demais, mas que merece ser retomada de acordo com seu objetivo central previsto na Constituição, já que norteia as demais peças. Pois, apesar desses limites, é possível vislumbrar as prioridades governamentais no documento.

Observamos que o PPA 2020-2023 apresenta uma simplificação dos dados e a ausência das concepções de muitos projetos propostos, além da falta de qualquer problematização da participação social, coerente com o profundo desprezo por espaços de controle democrático expresso desde o início do governo. Com o título "Planejar, Priorizar, Alcançar", o PPA de Bolsonaro contém 6 eixos, 13 diretrizes, 15 temas e 72 programas. Os eixos são: Institucional, Social, Ambiental, Infraestrutura, Econômico e Defesa. Apresenta três pilares 
de inovação: "Simplificação metodológica; Realismo fiscal; Alinhamento com os planejamentos estratégicos dos ministérios e integração com a avaliação de políticas públicas" (BRASIL, 2020, p. 4 - Apresentação).

Na prática, a simplificação significa uma nova metodologia de apresentação do orçamento, que desta forma dificulta o acompanhamento dos programas e ações até então desenvolvidos. A ênfase numa setorização simplista dos programas demonstra uma opção pela fragmentação da discussão política que compreende as dimensões tratadas, optando por um tecnicismo despolitizado no debate orçamentário.

Os primeiros anexos do PPA apresentam os chamados Programas Finalísticos (que anteriormente eram Programas Temáticos), no total de 66 e mais 4 programas de gestão (estes não apresentam metas, objetivos e indicadores). Nos anexos dos programas, o PPA de Bolsonaro não apresenta os indicadores e iniciativas de cada programa, como feito nos planejamentos dos governos anteriores, o que limita e obscurece ainda mais as informações sobre a perspectiva que se intenta com cada programa. A descontinuidade metodológica e ruptura com a série histórica tornam possível o ocultamento de dados que, além de fundamentais para garantir o princípio de transparência do orçamento, permitiriam a análise comparativa mais detalhada entre as propostas de diferentes governos para o orçamento público nos últimos anos.

A ênfase dos programas finalísticos concentra-se no Eixo econômico, que reúne $65,6 \%$ do total dos quase 7 trilhões previstos para os $4 \operatorname{anos}^{4}$, priorizando a gestão eficiente e equilíbrio dos gastos, típico da política ultraliberal. Até mesmo a política internacional é inserida neste eixo, o que limita sua concepção ao campo econômico. Já o eixo social ocupa o segundo lugar, recebendo pouco mais de um terço deste primeiro. Embora o eixo fale em bem-estar e em redução das desigualdades, seu escopo se limita aos seguintes temas: Educação, Saúde, Assistência Social, Cultura ${ }^{5}$ e Esporte, e Vínculos familiares e intergeracionais. Os temas de previdência e geração de emprego e renda estão no eixo

${ }^{4}$ A definição do eixo é "zelar pela integridade dos fundamentos da economia brasileira, com foco no crescimento econômico e na estabilidade fiscal e monetária. O eixo econômico incentiva o empreendedorismo, o fortalecimento da produtividade e a construção de soluções conjuntas e integradas entre o setor público e a iniciativa privada" (Brasil, 2020, p.4). Mais ultraneoliberal impossível, conforme vimos no item anterior.

5 A cultura dentro do Ministério da Cidadania se reduziu a um programa (5025) que contará em 2020 com apenas 2 milhões de reais e cujo objetivo é "promoção e defesa dos direitos humanos, com foco no amparo à família” (Brasil, 2020, p. 24), reafirmando a perspectiva conservadora deste orçamento. Os posicionamentos lamentáveis do governo Bolsonaro na relação com a cultura revelam-se coerentemente na matéria orçamentária. 
Econômico, desvinculando-os da perspectiva de direitos conforme a Constituição Federal de 1988 prevê.

Dentre as principais diretrizes do planejamento orçamentário sinalizadas no texto do PPA estão a modernização do Estado, a eficiência do gasto público (com redução da ingerência do Estado na economia), o equilíbrio das contas públicas, a ênfase na educação básica (sem citar o ensino superior), o estímulo ao empreendedorismo e, cabe ressaltar, a "simplificação e a progressividade do sistema tributário, a melhoria do ambiente de negócios, o estímulo à concorrência" (PPA, 2019, p. 3).

O texto da lei fala em "reforma tributária" para simplificar os tributos, tendo em vista reduzir custos do setor privado, aprofundando a concentração de renda e as desigualdades sociais no país. Enquanto isso, o grande foco é a família, vista como agente econômico, mas sem aporte suficiente do Estado. Quase todos os programas do campo social contam com alguma menção à família. Em linhas gerais, o orçamento para os próximos quatro anos caracterizase como parte da política ultraneoliberal em seu explícito apelo à redução da atuação estatal no campo social e afirma seu cariz conservador pela sua visão conservadora de família, patriarcal e mononuclear, sem remissão à função do Estado no campo dos direitos atinentes à sua proteção. Não há nenhuma menção a palavras como machismo, opressão, gênero, questão racial, orientação sexual. O que demonstra o lugar ocupado pelas mulheres e pelas opressões na visão deste governo.

Vejamos brevemente o que os dados brutos do PPA nos mostram. Nos interessa aqui analisar os dois principais eixos: Econômico e Social. Dos valores totais de 6,8 trilhões de reais para os 4 anos de governo, o eixo Social concentra $25,9 \%$,ou seja, 1,7 trilhões de reais, que estão concentrados em maior medida no Ministério da Cidadania (47\%) e no Ministério da Saúde (39,9\%), enquanto o Ministério da Educação ficará com 9,9\% dos recursos. Comparado ao PPA de 2016-2019 (batizado de "Desenvolvimento, produtividade e inclusão social"), os principais programas no campo da Saúde alocados neste ministério e que são destinados à garantia do SUS, apresentam um pífio aumento de pouco mais de 1\% no PPA de Bolsonaro. Este já é o reflexo do teto dos gastos aprovado em 2016 que passou a limitar as despesas primárias ${ }^{6}$. Sobre a educação, o efeito é ainda mais nefasto. Comparando o programa central da educação constante no

\footnotetext{
${ }^{6}$ A mudança significativa na metodologia dificulta imensamente a apreensão dos dados. A criação de novos programas nesta pasta inviabiliza o acompanhamento dos recursos e a análise comparativa, dificultando a exatidão nos números aqui expostos, o que não compromete a observação da tendência geral da alocação dos mesmos.
} 
orçamento (Educação de qualidade para todos) aos programas criados pelo novo governo, cujas definições e conjunção podem equiparar-se àquele, há uma redução de cerca de 12\%: de 199 bilhões para 175 bilhões de reais.

No Ministério da Cidadania, o maior em termos orçamentários dentro do eixo Social, percebemos uma série de programas que antes estavam relacionados a outros órgãos e unidades orçamentárias. Isso significa que há uma superlotação de programas neste ministério, com a desculpa da simplificação do orçamento, para apresentar o verniz social de um governo neofascista. Cultura e esporte são programas que estão alocados na pasta da Cidadania, que concentra atividades antes desenvolvidas por ao menos quatro ministérios extintos: Desenvolvimento Social, Justiça e Cidadania, Cultura e Esporte. Embora com grande aporte de recursos na totalidade, percebemos que alguns programas apresentam redução, como o caso do Bolsa Família (de 123 bilhões para 120 bilhões) e outros têm uma tímida participação na pasta, como o programa "Promoção à cidadania" e o "Rede de Suporte Social ao Dependente Químico: cuidados, prevenção e reinserção social”, ambos com cerca de 300 milhões para 4 anos.

Outro dado importante a destacar deste orçamento refere-se à exclusão de diversos programas fundamentais, como o programa voltado ao combate à violência contra mulher, o programa de promoção de igualdade racial e o programa em defesa dos direitos humanos da criança e adolescente. Neste campo, o programa recém-criado se limita à "Atenção integral à primeira infância", contrariando a perspectiva presente no Estatuto da Criança e Adolescente (ECA) sobre a garantia de direitos a infância e adolescência na sua integralidade.

No Eixo econômico (que concentra $64,7 \%$ dos recursos para os 4 anos, ou seja, 4,4 trilhões de reais) o maior programa é a "Nova Previdência". Com o fim do ministério, esta política se encontra na pasta econômica, destituída da perspectiva de direito integrante da Seguridade Social presente na Constituição, e cuja diretriz passa a ser a "garantia do equilíbrio das contas públicas, com vistas a reinserir o Brasil entre os países com grau de investimento" (PPA 2020, anexo I, p. 43). Junto à temática da moradia e transporte público, a previdência aparece como alavanca da economia e garantidora das metas fiscais. A (contra) reforma da previdência aprovada em 2019 já desconsiderava esta política como direito social e o PPA 2020-2023, do governo Bolsonaro, institucionaliza esta perspectiva.

Lei de Diretrizes Orçamentárias (LDO) para 2020 previa um déficit primário de 124 bilhões de reais. Otimista quanto à projeção do PIB, apontava 
crescimento de 2,7\% em 2020, o que não se confirma atualmente em que, após a inflexão da pandemia, se noticia a estimativa de que o PIB tenha uma queda em torno de $5 \%$ a $10 \%$, de acordo com a versão menos ou mais pessimista. Seguindo na perspectiva ultraneoliberal, a LDO defende a chamada "Reforma" da Previdência como prioridade para a execução do dito equilíbrio fiscal, o que, como vimos, reitera as tendências do período de ajuste fiscal permanente. Além dela, a equipe de Bolsonaro apresenta um combo de contrarreformas para complementar tal objetivo: a reforma tributária (com simplificação de impostos e redução do princípio da transparência); a desmobilização de ativos (com redução do número de empresas estatais); o aumento da liberalização comercial; a formalização da autonomia do Banco Central e a reforma administrativa.

PEC do Pacto Federativo (188/2019), ganhou destaque no texto da LDO e tem sido até agora a grande prioridade do governo, cuja finalidade será "aprofundar a racionalização para alcançar também os equipamentos públicos presentes em todo o território nacional e eliminar sobreposições e redundâncias". Nos remete, como vimos no item anterior, ao Plano Diretor do Estado de Bresser Pereira, do ano de $1995^{7}$. Neste caso, a contrarreforma proposta por Bolsonaro opera sobre aquilo que sobrou do equipamento estatal, fundamentalmente os equipamentos destinados à reprodução da classe trabalhadora, como o caso da educação superior e o SUS, além do Banco do Brasil e Petrobrás (ambos de caráter misto, mas agora nitidamente pretende-se radicalizar nas suas privatizações).

As contrarreformas justificam-se, como vimos, pelo argumento da contenção da dívida pública, cuja explicação para elevação recai nos "exorbitantes" gastos do Estado brasileiro, que para tanto, deve economizar para pagar a própria dívida. Aqui o governo apresenta uma espiral da dívida às avessas: o gasto público gera dívida, que, portanto, deve ser contido para pagá-la. Com a elevação do estoque da dívida de 2018 para 2019 em 10\% (INESC, 2020), o projeto de reforma administrativa operacionalizará o aparelhamento do fundo público para o capital portador de juros na sua quase totalidade.

Tratando agora da execução orçamentária de 2019, esta apresentou um crescimento ínfimo de $0,41 \%$, dez vezes menos que a inflação daquele ano que ficou em 4,31\%. Isso significa que não houve aumento, e sim desfinanciamento das políticas públicas. No campo dos gastos sociais, nas chamadas despesas discricionárias (ou seja, não obrigatórias por lei) houve uma redução de 8,55\% comparado a 2018 , com destaque para educação que teve queda de $16 \%$.Fica

\footnotetext{
${ }^{7}$ Ver Behring, 2008.
} 
claro então, que o orçamento do governo Bolsonaro omite na letra do texto e limita no orçamento qualquer possibilidade de garantia direitos sociais orientados pelos princípios da Constituição Federal. A Seguridade Social caminha para restringir-se à política de mitigação dos efeitos mais deletérios das desigualdades sociais, que tenderão a ser aprofundadas por este governo.

\section{Contrarreforma da previdência: o maior ataque de Bol- sonaro e Guedes às políticas sociais}

Até o momento, o mais bem-sucedido ataque aos direitos sociais do governo Bolsonaro foi sua contrarreforma da Previdência. As inúmeras contrarreformas da Previdência Social, implementadas por todos os governos desde Cardoso, compõem com centralidade o ajuste fiscal permanente no país. Isso porque a Previdência Social reúne grandes fundos de recursos apropriados pelo Estado do trabalho necessário, na sua forma salário, do conjunto dos trabalhadores. O sentido, então, dessa verdadeira "contrarreforma permanente" da Previdência Social sempre é a ampliação das contribuições, parcelas de salários que irão compor os fundos públicos, e redução de direitos para que os recursos possam ser liberados para dar suporte ao capital.

A apropriação de fundos previdenciários pelo capital não é novidade. Esses recursos foram, mesmo antes da Constituição de 1988, suporte para programas de habitação popular, que favoreceram o grande capital da construção civil e para a expansão do capital privado na saúde, que era, e ainda é contratado pelo Estado para atender aos trabalhadores. O que é novo sob o neoliberalismo é a apropriação desses fundos pelo capital financeiro, que passa a ser hegemônico no período neoliberal do capitalismo.

Isso ocorre de duas formas. O discurso da crise e do déficit da Previdência e a precarização das relações de trabalho que desvincula os trabalhadores dessa política, vêm desmoralizando a Previdência Social como política social justa e sustentável, o que estimula os trabalhadores a aderirem diretamente aos fundos de investimentos de alto risco, travestidos de "previdência privada" aberta, comprados diretamente de instituições financeiras.

Por outro lado, os fundos previdenciários públicos, compostos por contribuições obrigatórias vinculadas ao salário de trabalhadores que ainda têm contratos formais, por meio do Regime Geral de Previdência Social (RGPS) gerido pelo Instituto Nacional de Seguridade Social (INSS) e trabalhadores públicos dos municípios, dos estados e da União, por meio de seus Regimes Próprios 
de Previdência Social (RPPS), vão sendo paulatinamente transformados em fundos de pensão, ou "previdências privadas" fechadas. Para os trabalhadores do Estado, esse processo estava em curso nas estatais desde a década de 1970 e foi previsto para os trabalhadores do RJU desde a EC 20/98, aprovada durante o governo Cardoso. As contrarreformas dos governos do PT consolidaram esse processo com a criação da famigerada Fundação de Previdência Complementar do Servidor Público Federal (Funpresp) pelo decreto 7808/2012, seguido pela formação de diversos outros fundos de pensão financeirizados em estados e municípios.

Além disso, os fundos de Previdência dos trabalhadores do serviço público em todas as esferas, já vinham tendo seus recursos capitalizados por meio da aplicação de suas receitas em mercados financeiros, possibilidade aberta pela Lei 9717/98, posterior a EC 20/98 de Cardoso, que regulamentou a criação dos fundos dos RPPSs.

No Rio de Janeiro, por exemplo, durante o governo Cabral, a partir de 2013, o fundo ainda público, formado pela contribuição compulsória dos salários dos trabalhadores entre outras receitas, como os royalties do petróleo, foi utilizado como garantia para securitizações e antecipações de receita, na prática uma nova forma de aquisição de dívida pública com apropriação de grandes volumes de fundo público para pagamento de juros. As operações se tornaram objeto de uma Comissão Parlamentar de Inquérito (CPI), dada uma série de irregularidades apontadas pelo Ministério Público e pelo Tribunal de Contas do Estado, que só favoreceram o mercado financeiro (Cislaghi, 2019).

A contrarreforma do governo Bolsonaro, ainda que mais acentuada que as de governos anteriores, só foi possível porque se beneficiou da estrada de financeirização já aberta (Andes, 2020). A proposta foi apresentada em 20 de fevereiro de 2019, com menos de dois meses, portanto, do início de seu governo. Seu projeto original propôs não só alterações nos direitos previdenciários, mas ainda, em direitos assistenciais, como a redução do valor do BPC. Seu objetivo principal, porém, era a generalização da capitalização da Previdência Social pública, já iniciada por governos anteriores.

Promulgada pelo Congresso Nacional em 12 de novembro de 2019, a emenda aprofundou de modo dramático as dificuldades para a aposentação, ainda que tenha recuado em relação à proposta original em alguns pontos, pela pressão social contra sua perversidade. Em síntese, as mudanças aprovadas ampliaram o tempo mínimo de contribuição para 40 anos, para que o valor do benefício corresponda a $100 \%$ da média dos salários na ativa, instituíram uma idade mínima para a aposentadoria de 65 anos para homens e 62 anos para mulhe- 
res, reduziram o valor das pensões, elevaram o valor das alíquotas de contribuição. Ou seja, os trabalhadores terão que contribuir mais e por mais tempo para receber benefícios menores e mais tardiamente.

Em relação ao aumento da idade mínima, a proposta original equiparava homens e mulheres alegando que as desigualdades nas suas atividades laborais não justificariam qualquer diferenciação, desconsiderando a sobrecarga do trabalho doméstico de reprodução social que recai de forma não remunerada sobre as mulheres, evidenciando a orientação misógina desse governo.

No tocante à capitalização da Previdência Social de forma generalizada, as novas regras não foram completamente aprovadas. No caso dos trabalhadores do serviço público, os entes estaduais e municipais que ainda não possuem "previdências privadas" terão que obrigatoriamente criá-los, ou aderir a fundos já existentes, instituindo, assim, o teto previdenciário para seus trabalhadores, em no máximo dois anos. Esses fundos de pensão não precisarão ser necessariamente públicos, mas poderão ser diretamente entregues às instituições financeiras, resolvendo em favor destas a disputa desses recursos com a burocracia sindical que os geriu até então (Andes, 2020).

Ainda que a privatização por capitalização não tenha sido total, a EC 103/19 desconstitucionalizou a Previdência Social, pois autorizou que mudanças futuras nesse sentido possam ser realizadas por leis complementares, com menos debate e votação por maioria simples no Congresso Nacional.

Gentil (2019) aponta que a degradação das receitas da Seguridade Social no Brasil, e em particular as receitas da Previdência Social, é uma estratégia clara do Estado para permitir o avanço do capital financeiro sobre os recursos das políticas sociais. No caso da Previdência, os fundos de capitalização são os principais beneficiados, seja pela privatização dos fundos de pensão fechados, seja pela ampliação de mercado para os fundos privados abertos. O patrimônio líquido dos fundos de previdência abertos passou de 23 bilhões de reais em 2002 para 490 bilhões de reais, em 2015, ou seja, um crescimento verdadeiramente espantoso. Os fundos de "previdência privada" converteram-se nos maiores proprietários de títulos da dívida pública federal, participação que passou de $17,7 \%$ do total desses ativos em 2007 , para $24,5 \%$ em 2016 . A carteira de investimentos do Funpresp era composta em 96,5\% por títulos da dívida federal, ao final de 2017 (Gentil, 2019, p.196).

Esses dados deixam evidente que o sentido das contrarreformas é a retirada de direitos dos trabalhadores para alimentar o capital financeiro com fundo público, de forma cada vez mais aprofundada pelo ultraneoliberalismo atual. Os trabalhadores têm seus salários expropriados para fundos capitalizados, cujo 
sucesso depende de maior apropriação do orçamento federal na forma de juros da dívida pública, o que contraditoriamente significa menos direitos e mais precarização dos serviços públicos e dos direitos de seus trabalhadores. Com a capitalização da Previdência Social, o governo deixa de pagar diretamente aposentadorias e pensões, mas continua a pagá-las, com o intermédio dos fundos donos da dívida pública, com custos elevadíssimos.

\section{Considerações Finais}

Em linhas gerais, essas são as propostas ultraneoliberais em curso. Será que elas buscam atender ao objetivo de equilíbrio/estabilidade fiscal? Somos da opinião de que serão ineficazes quanto a este objetivo, mas muito consistentes para socializar o custo da crise com os trabalhadores, e ainda mais após a pandemia. A contrarreforma do Estado de FHC, a partir de 1995, anunciava o controle da dívida para ter recursos para investimentos. Todas as medidas ali previstas foram tomadas e esses objetivos não foram efetivamente alcançados. Já a transferência de 49 bilhões de dólares em patrimônio público para mãos privadas foi um estrondoso sucesso. O destino do "combo de horrores" de Guedes tende a ser o mesmo. Ademais, nos perguntamos se medidas drásticas e que culpabilizam os trabalhadores do serviço público seriam realmente necessárias. O discurso presidencial de que "não há dinheiro para nada" é uma falácia. A conta que fazem reduz os gastos públicos aos gastos primários correntes, deixando de lado a monumental gambiarra de recursos que é o pagamento de juros, encargos e amortizações da dívida pública, o primeiro item de gasto do governo federal, e que retira em média $30 \%$ a $40 \%$ do orçamento brasileiro variando ano a ano para menos ou mais. Nenhuma dessas medidas coloca a dívida em xeque, pelo contrário: mantém o país refém desta lógica, inclusive extinguindo fundos para continuar pagando, remunerando o capital portador de juros, às custas da expropriação de milhões de trabalhadores(as). Uma dívida que jamais foi auditada. Portanto, são medidas que na prática "enxugam gelo" no que se refere ao déficit das contas públicas, ao passo em que socializam os custos da crise.

Enquanto o pacote foi tratado em 2019 pela grande imprensa como algo do "governo que trabalha", apesar de algumas fricções pontuais com os "excessos" presidenciais - que, diga-se de passagem, se tornaram mais e mais frequentes desde então -, a verdadeira emergência, a social, foi ganhando contornos cada vez mais dramáticos e explosivos: as gigantescas filas do auxílio 
emergencial no contexto da pandemia, demandado por 70 milhões de pessoas, de 600,00, e arrancado do governo que queria o valor de 200,00, são inequívocas. As notícias são alarmantes, pois a pandemia se encontrou com um país já dilacerado: os trabalhadores(as) sem carteira assinada e sem direitos já somavam em 2019 o recorde de 11,8 milhões (sem contar desalentados e outras categorias do IBGE), e este tem sido o resultado da contrarreforma trabalhista; em São Paulo um(uma) trabalhador(a) da periferia ou de comunidades pobres vive 20 anos a menos que nos bairros de classe média e alta, o que nos mostra o impacto da contrarreforma da previdência sobre estes setores, destacadamente as mulheres e negros(as), que dificilmente conseguirão contribuir por 15 ou 20 anos, quanto mais por 40 anos para ter acesso ao teto; metade dos brasileiros vivem em média com R \$413,00, dado da PNAD/IBGE e que se relaciona à passagem, desde 2015, de um milhão de pessoas por ano para abaixo da linha de pobreza; o número de ambulantes aumentou em 510\% no mesmo período. Frente a isso, a resposta de Guedes foi colocar em questão, em 2019, porque os pobres não têm poupança (SIC!) e propor o congelamento do salário mínimo. Trata-se do mais profundo darwinismo social ultraneoliberal, de um ataque inédito aos trabalhadores(as) do setor público e privado. É uma imensa tragédia e esse projeto não tem nenhuma condição de enfrentar o desemprego que cresceu ainda mais após a pandemia. Não tem sequer o desejo, já que se orienta por uma visão meritocrática, segundo a qual o desemprego é um problema individual e os bens e serviços devem ser acessados no sacrossanto mercado deificado. O que vemos como precarização e trabalho sem direitos, eles veem como empreendedorismo. Há outras dimensões da recente tragédia brasileira que não analisamos neste artigo, a exemplo da relação entre ultraneoliberalismo e neofascismo, com uma caracterização mais detida da dimensão política deste processo, que envolve evidentemente seguidas derrotas dos trabalhadores. Alguns elementos deste debate podem ser buscados no conjunto de textos reunidos em Cislaghi e Demier (Orgs.), 2019. Mas não podemos deixar de registrar os ataques do governo brasileiro às mais elementares liberdades democráticas e à Constituição de 1988 neste período da pandemia, bem como a militarização do Estado e o armamento de milícias de extrema direita no país, acompanhados de uma resposta institucional débil. Finalizamos este artigo apontando que há uma correspondência entre este Estado interditado e asfixiado para o social e o público, engendrado pelo ultraneoliberalismo e a restrição das liberdades democráticas preconizada pelo neofascismo, para os quais devemos estar atentos e fortes. 


\section{Referências}

ANDES - SINDICATO NACIONAL DOS DOCENTES DAS INSTITUIÇÕES DE ENSINO SUPERIOR (BRASIL). Financeirização nos Regimes Próprios de Previdência Social (RPPS) nos estados e tendências enunciadas na estruturação do sistema e na legislação. In: Sindicado Nacional dos Docentes das Instituições de Ensino Superior (Brasil). Brasília: Sindicado Nacional dos Docentes das Instituições de Ensino Superior, 2020.

BEHRING, Elaine Rossetti. Brasil em Contra-reforma: desestruturação do Estado e perda de direitos. 2. ed. São Paulo: Cortez, 2003

. Ajuste Fiscal Permanente e contrarreformas no Brasil da redemocratização. In: SALVADOR, Evilásio, BEHRING, Elaine e LIMA, Rita de Loudes (Org.). Crise do capital e fundo público: implicações para o trabalho, os direitos e a política social. São Paulo: Cortez, 2019. p. 43-65.

BEGHIN, Nathalie. O PPA do governo Bolsonaro: 4 anos de miséria. Net, maio. 2020. Disponível em: < https://www.inesc.org.br/o-ppa-do-governo-bolsonaro-4-anos-de-miseria/> Acessado em: 22 maio. 2020.

BRAGA, Ruy. A política do precariado: do populismo à hegemonia lulista. São Paulo: Boitempo, 2012.

BRASIL. PPA 2020-2023: planejar, priorizar, alcançar. Ministério da Economia. Net, maio. 2020. Disponível em: < https://www.gov.br/economia/pt-br/assuntos/planejamento-e-orcamento/plano-plurianual-ppa> $>$. Acesso em: 22 maio. 2020.

Lei $\mathrm{n}^{\circ}$ 13.898/2019 (Lei Ordinária), de 11 de setembro de 2019 (Lei de Diretrizes Orçamentárias). Ministério da economia, Brasília, DF. Disponível em: < https://www2.camara.leg.br/orcamento-da-uniao/leis-orcamentarias/ldo. $>$ Acesso em: 22 maio. 2020.

CISLAGHI, Juliana Fiuza. Financeirização da Previdência Social no Brasil: um estudo sobre o estado do Rio de Janeiro. In: SALVADOR, Evilásio; BEHRING, Elaine e LIMA e Rita de Loudes (Org.). Crise do capital e fundo público: implicações para o trabalho, os direitos e a política social. São Paulo: Cortez, 2019. p. 123-139.

. Do neoliberalismo de cooptação ao ultraneoliberalismo: respostas do capital à crise. Net, junho 2020. Disponível em: $<\underline{\text { https: //esquerdaon- }}$ 
line.com.br/2020/06/08/do-neoliberalismo-de-cooptacao-ao-ultraneoliberalismo-respostas-do-capital-a-crise/>. Acesso em: 09 jun. 2020. e DEMIER, Felipe (Orgs.). O Neofascismo no Poder (Ano I). Análises críticas sobre o Governo Bolsonaro. Rio de Janeiro: Consequência, 2019.

DARDOT, Pierre e LAVAL, Cristian. A nova fase do neoliberalismo. Net, jun. 2017. Disponível em: < https://racismoambiental.net.br/2019/07/30/dardot-e-laval-a-nova-fase-do-neoliberalismo/> Acesso em: 08 jun. 2020.

DEMIER, Felipe. Depois do Golpe: a dialética da democracia blindada no Brasil. Rio de Janeiro: Mauad X, 2017.

FRASER, Nancy. O feminismo, o capitalismo e a astúcia da História. Revista Outubro. n. 26. p. 11-26. 2016.

GENTIL, Denise Lobato. A política fiscal e a falsa crise da Seguridade Social brasileira: uma história de desconstrução e de saques. Rio de Janeiro: Mauad X, 2019.

GERBASE, Livi. Orçamento 2020: quais as previsões para o ano que chega?.Net, maio. 2020. Disponível em: < https://www.inesc.org.br/orcamento2020-quais-as-previsoes-para-o-ano-que-chega/>. Acesso em: 22 maio. 2020. INSTITUTO DE ESTUDOS SOCIOECONÔMICOS (BRASIL). O Brasil com baixa imunidade: balanço do Orçamento Geral da União 2019. In: Instituto de Estudos Socioeconômicos (Brasil). Publicação. Brasília: Instituto de Estudos Socioeconômicos, 2020. Disponível em: < https://www.inesc.org.br/ obrasilcombaixaimunidade/>. Acesso em: 26 maio. 2020.

OLIVEIRA, Francisco. Crítica a razão dualista: o ornitorrinco. São Paulo: Boitempo, 2003.

OLIVEIRA, Gênesis. Fundo Público e crise do capital: expropriação e flexibilização dos direitos dos servidores públicos. Tese (Doutorado em Economia) - Universidade do Estado do Rio de Janeiro, Rio de Janeiro, 2019. 
